\title{
RESTORATION OF MALARIA CONTROL IN THE MADAGASCAR HIGHLANDS BY DDT SPRAYING
}

\author{
C. F. CURTIS \\ London School of Hygiene \& Tropical Medicine, London, United Kingdom
}

The coastal areas of Madagascar have stable malaria like much of lowland tropical Africa. However, the highlands (1000-1500 meters) had unstable seasonal Plasmodium falciparum malaria since its arrival in the $19^{\text {th }}$ century when rice growing was introduced there. ${ }^{1}$ At the end of the French colonial era in the $1950 \mathrm{~s}$, malaria and its main vector Anopheles funestus were suppressed to near or complete eradication in the highlands. This was achieved by spraying DDT mixed with $\gamma \mathrm{HCH}$ in over a million houses and mass chemoprophylaxis of schoolchildren with chloroquine given 3 times per week at 2375 schoolchildren's treatment centers. ${ }^{2}$ In Antananarivo province the percentage of positive blood slides was reduced from $25-35 \%$ in the late 1940 s to $0.18 \%$ (6 positive among 3348 slides from children aged 2-10 years) in 1955. An. funestus, which had been abundant resting in highland houses in the 1940s, could not be found in the region in $1955 .^{2}$ Some spraying continued and there were centers at which chloroquine was available until the late 1970 s, when these measures were, regrettably, abandoned. ${ }^{1}$ An. funestus crept back into the area between 1976 and the 1980s. A sporozoite positive individual was found in 1987 and a plea was then made for urgent introduction of control measures. ${ }^{3}$ This plea was not heeded in time and an explosive epidemic hit the highland region in the late 1980s, the prevalence of parasitemia returned to the levels seen in the 1940 s and tens of thousands died among the, by then, nonimmune population. ${ }^{1}$

In response to this disaster, a program, assisted by the Italian aid agency and World Bank, restored surveillance, DDT spraying and the making of chloroquine widely available in all 27 districts of the highland region. In this issue, Romi et al. ${ }^{4}$ report data showing how well these measures have succeeded in bringing malaria and its main local vector back under control. The parasite prevalence in children in 1998-2000 was almost as low as it had been in 1955 and An. funestus populations were greatly reduced, though there could not be said to have been "disappearance" of this species in the highlands, as was said in $1955 .^{2}$ Thus this seems to be another case where the best modern malaria control efforts can barely match what was routinely achieved 40 years ago. ${ }^{5}$ In the Madagascar highlands a system for making anti-malaria drugs available, surveillance and focal spraying has been left in place and it is to be hoped that complacency and economic difficulties will not once again allow An. funestus and malaria to creep back and then explode.

It is rumored that international organizations tried unsuccessfully to pressure the Madagascan government into using a far more expensive insecticide than DDT for the house spraying program. However, the Madagascan government approved the use of DDT. The Madagascan story, as well as recent events in KwaZulu Natal, South Africa, ${ }^{6}$ are good examples of where restoration of DDT spraying programs has been needed to deal with malaria problems which had earlier been controlled and had then got out of hand. It should be emphasised that use of DDT for vector control now has explicit legal backing. This follows the inclusion, during the final round of negotiations in Johannesburg in December 2000, of an amendment to the International Treaty on Persistent Organic Pollutants which exempts DDT for vector control from being banned. It is increasingly recognised that the evidence of harmfulness of DDT to non-target organisms came from when great quantities were used in open fields in the 1950s and 60s. There is very little evidence for harmfulness when DDT is used indoors against Anopheles mosquitoes. ${ }^{7}$ In recent years WHO has been indecisive on this issue and failed to produce a report in time for the Johannesburg negotiations on an expert consultation held more than a year earlier. However, the message now seems to be getting through to the international organizations and the case for allowing the use DDT against malaria vectors is clearly made in the 2001 UNDP World Development Report. $^{8}$

Author's address: C. F. Curtis, London School of Hygiene \& Tropical Medicine, Disease Control \& Vector Biology Unit, Room 419, Keppel Street, London WC1E 7HT, United Kingdom, E-mail: Chris.Curtis@1shtm.ac.uk.

\section{REFERENCES}

1. Mouchet J, Laventure S, Blanchy S, Fioramonti R, Rakotonjanabelo A, Rabarison P, Sircoulon J, Roux J, 1997. La reconquête des Hautes Terres de Madagascar par le paludisme. Bull Soc Path Ex 90: 162-168.

2. Joncour G, 1956. La lutte contre le paludisme à Madagascar. Bull Wld Hlth Org 15: 711-723.

3. Fontenille D, Rakotoarivony I, 1988. Reappearance of Anopheles funestus as a malaria vector in the Antananarivo region, Madagascar. Trans Roy Soc Trop Med Hyg 82: 644-645.

4. Romi R, Razaiarimanga MC, Raharimanga R, Rakotondraibe EM, Ranaivo LH, Pietra V, Raveloson A, Majori G, 2001. Impact of the malaria control campaign (1993-1998) in the highlands of Madagascar: parasitological and entomological data. Amer J Trop Med Hyg 66: 2-6.

5. Curtis CF, Mnzava AEP, 2000. Comparison of house spraying and insecticide-treated nets for malaria control. Bull Wld Hlth Org 78: 1389-1410.

6. Hargreaves K, Koekmoer LL, Brooke BD, Hunt RH, Mthembu J, Coetzee M, 2000. Anopheles funestus resistant to pyrethroids in South Africa. Med Vet Ent 14: 181-189.

7. Curtis CF, Lines JD, 2000. Should DDT be banned by international treaty? Parasit Today 16: 119-121.

8. United Nations Development Programme, 2001. World Development Report 2001: making new technologies work for human development, p. 69. 